\title{
激励机制在行政事业单位人力资源管理中的运用分析
}

\author{
张德香 \\ 青岛莱西市望城街道办事处便民服务中心，山东青岛 266601
}

[摘要]近年来, 我国综合国力在多方面利好因素的影响下, 得到了全面的发展进步, 在这个过程中行政事业单位在其中起到 了重要的影响作用。要想保证行政事业单位能够保证稳定健康的发展, 那么最为重要的就是需要制定切实可行的人力资源管 理制度，而激励机制在人力资源管理工作中的作用是非常巨大的，其实质就是利用诸多相关激励方式来激发员工工作的主动 性，促使工作整体效率的不断提升，引导员工能够树立正确的工作意识。在社会经济飞速发展的影响下，我国行政管理改革 工作得以大范围的实施, 这样不但为我国事业单位的发展带来了良好的机遇, 并且也推动了我国事业单位人力资源激励机制 的发展壮大。与此同时, 其中涉及到的诸多隐形风险问题也随之出现, 需要我们加以切实的解决。

[关键词]事业单位; 人力资源管理; 激励机制; 问题; 措施

DOI：10.33142/mem.v2i1.3373 中图分类号: D630.3 文献标识码：A

\section{Analysis on the Application of Incentive Mechanism in Human Resource Management of Public Institution}

\author{
ZHANG Dexiang
}

Convenient Service Center of Qingdao Laixi Wangcheng Sub-district Office, Qingdao, Shandong, 266601, China

\begin{abstract}
In recent years, under the influence of many favorable factors, Chinese comprehensive national strength has achieved comprehensive development and progress, in which the administrative institutions play an important role. In order to ensure the stable and healthy development of administrative institutions, the most important thing is to develop a practical human resource management system, and the role of incentive mechanism in human resource management is very huge. Its essence is to use a lot of relevant incentive methods to stimulate the initiative of employees, promote the continuous improvement of the overall efficiency of work, and guide the development of human resource management guide the staff to establish a correct sense of work. Under the influence of the rapid development of social economy, Chinese administrative reform can be implemented in a wide range, which not only brings good opportunities for the development of Chinese institutions, but also promotes the development of Chinese institutions' human resource incentive mechanism. At the same time, there are many hidden risks involved, which need to be solved.
\end{abstract}

Keywords: Public Institution; human resource management; incentive mechanism; problems; measures

\section{引言}

在社会经济水平不断提升的带动下, 事业单位发展也取得了良好的成绩, 在事业单位发展过程中, 人类资源作用 十分的关键。激励机制在人力资源管理中的作用是非常重要的, 借助激励机制不但能够有效的激发员工的工作积极性, 并且对于促进事业单位稳步健康发展也能够起到良好的作用。但是就现如今事业单位实际情况来说, 人力资源管理中 的激励机制整体水平还没有达到完善的状态, 其中还存在诸多的问题需要我们加以切实的解决。所以, 我们还需要围 绕人力资源管理中激励机制展开切实的深入的研究分析, 综合各方面实际情况和需要来对激励机制加以优化和创新, 将激励机制的作用切实的发挥出来。

1 激励机制的主要内容

激励机制其实质就是在具有一定完整性的系统之中, 利用科学高效的方式方法对主体工作积极性加以调动, 将主 体的作用切实的施展出来。将激励机制在事业单位人力资源管理中加以切实的运用, 不仅能够协助员工对工作加以全 面的了解, 并且还可以增强员工对自身工作的正确认知, 促使员工能够全身心的参与到日常用作之中。通常来说, 只 有能够切实的调动员工工作主动性的激励机制才算是合格的激励机制, 所以怎样提升激励机制的作用, 还需要事业单 位管理工作人员对员工实际需要加以全面的了解 ${ }^{[1]}$ 。 


\section{2 事业单位人力资源管理中激励机制存在的问题}

\section{1 激励方式存在问题}

就现如今实际情况来看, 我国一些事业单位对于人力资本的概念缺少全面的了解, 事业单位对于人才激励十分的 忽视, 在我国事业单位内部, 专业人才和技术类人才圆乏的问题十分的严重。当下, 我国事业单位人力资源管理工作 中, 激励方式方法较为老旧落后, 缺少基本的创新, 激励方案通常都是选择物质奖励的方式。无论是企业单位还是事 业单位, 员工工作的主要目标就是能够获取需要的经济利益, 但是针对优秀员工进行精神激励也是十分必要的。在社 会快速发展的影响下, 职工综合素质整体水平得到了全面的提升, 如果单纯的利用奖金的激励方式很显然以及无法在 满足人力资源管理工作的需要了, 必然会造成员工职业技能发展滞缓的情况发生, 这也是导致大量职工离职的主要根 源。当下所执行的各类激励方式中, 技术工作人员和行政人员工作实际方式存在一定的类似性, 从而使得员工因为对 激励方式存在不满的情况会选择跳槽。这就充分的表明了, 事业单位在实施人力资源管理工作的时候, 务必要结合实 际情况选择运用适当的方式方法, 这样才能将激励机制的作用切实的发挥出来, 从而不断提高事业单位人力资源管理 工作的整体水平 ${ }^{[2]}$ 。

\section{2 激励体制未得到真正的落实}

就现如今实际情况来说, 我国大部分事业单位配套设施与社会发展需要存在一定的差距, 一些事业单位往往都会 因为资金不到位, 而无法为员工创作良好的办公环境, 这样对于提升工作效率就会造成诸多的阻碍, 并且也会损害到 工作人员的工作积极性。当下, 事业单位内部工作环境为人力资源管理激励工作的实施造成了诸多的限制, 在事业单 位各个配套设施中, 事业单位员工无法将自身的工作潜能充分的发挥出来 ${ }^{[3]}$ 。

\section{3 激励体制问题}

首先, 在社会快速发展的形势下, 事业单位单纯的利用奖金的形式来调动员工工作积极性这种方式逐渐的小事, 由于事业单位在实施激励工作的时候, 可以使用的资源具有一定的有限性, 职工在得到奖金激励之后, 没有得到任何 的精神奖励。当前, 员工的工作的认可要相对简单的物质激励作用更好。其次, 就事业单位实际情况来看, 人力资源 管理机制的核心都集中在经济激励方面, 对于员工的精神激励较为忽视, 这样就造成了事业单位人力资源管理中激励 机制效果较差的不良后果。

\section{3 完善人力资源激励机制的相关措施}

\section{1 树立以人为本的激励管理理念}

在事业单位内部实施人力资源管理工作的时候, 务必要秉承以人为本的原则, 工作的开展需要以员工为核心, 为 事业单位设立完善的激励机制的人才管理体系创造良好的条件。其次, 需要引导各个公共部门的上层管理人员对于激 励机制在管理工作开展中所起到的重要影响作用加以正确的认识。从设立完善的激励方案为基础, 避免制度化人力资 源激励盲目机械实施的情况发生 ${ }^{[4]}$ 。

\section{2 激励机制形式的多样化}

人力资源管理机制落实过程中, 可选择的激励方式多种多样, 以往很多的事业单位激励管理部门对于物质激励较 为重视, 而对于精神激励十分的忽视。无机奖励的方式大都是工资、奖金、股票等形式, 而精神激励的方式十分单一, 并且精神激励管理工作整体水平较差, 不具备持续激励的作用。其次, 一些事业单位激励机制不具备良好的针对性, 激励的方式无法结合员工实际需要来落实, 为了实现激励管理机制有效性必须最大限度地提高人力资源管理的激励机 制, 注意促进形式的多元化, 既要在管理中注意物质激励, 还要关注精神奖励, 要认识到钱不是最有效的激励方法, 精神激励的作用不容忽视。因此, 在人力资源管理的激励机制方面, 我们必须在物质激励和精神动力方面基于员工的 需求, 结合工作绩效实施目标和环境激励, 来促进和增强员工的团结和凝聚力 ${ }^{[5]}$ 。

\section{3 兼顾绩效和激励的两步法}

奖惩的标准和激励机制密切相关, 同时绩效的考核项目要保证透明化和标准化, 流程是公开的。根据员工的工作 态度、工作质量、绩效、热情等方面进行全面评价绩效考核制度, 这一过程中必须有专业的部门进行公平、公开、公 正的评估, 从而确定员工绩效水平的真实有效性。在评估管理体系进行奖惩措施后, 使员工得到公平的评价获得相应 
的激励, 也使其他员工从中得到激励, 使员工能够不断进步, 满足员工的发展需求, 通过绩效评估和激励机制, 从而 最大限度地调动所有部门员工的积极性，促进工作整体效率的提升。

\section{4 结论}

总的来说, 激励机制的合理的运用在推动我国事业单位人力资源管理工作水平和效率的提升能够起到积极的影响 作用, 所以事业单位应当加大力度针对激励机制加以优化完善, 从而为我国事业单位的未来稳步健康发展打下坚实的 基础。在实际开展员工激励工作的时候, 需要秉承以人为本的原则, 科学落实各项工作, 提升事业单位人力资源管理 工作的整体水平。

\section{[参考文献]}

[1]黄初伟.事业单位人力资源管理中的激励机制研究 [J].内蒙古煤炭经济, 2019(23): 85-86.

[2]冯晓光.浅谈行政事业单位人力资源管理中的激励机制 [J].现代经济信息, 2019(20): 42-45.

[3]王振荣. 探讨行政事业单位中人力资源管理的激励机制 [J]. 经济师,2019(10): 266-267.

[4]潘穗榕.事业单位人力资源管理中激励机制的思考 [J].中国市场,2018(12): 97-99.

[5]胡丽虹. 我国行政事业单位人力资源管理的问题及对策研究 [J]. 山西经济管理干部学院学报, 2016,24(2): 9-12.

作者简介: 张德香 (1978.11-) 女, 毕业院校; 长春工业大学 所学专业法学, 当前就职单位, 青岛莱西市望城街道办 事处便民服务中心，职务：便民服务中心主任，职称级别：中级经济师八级。 